\title{
New clinical method for measuring the rate of gastric emptying: the double sampling test meal
}

\author{
J. D. GEORGE \\ From the Department of Surgery, Institute of Clinical Science, \\ Royal Victoria Hospital, Belfast
}

A resurgence of interest in gastric emptying has developed, due mainly to its possible aetiological significance in gastric ulceration. Many techniques have been used to measure the rate of emptying but few clinical methods, which determine both the rate and pattern of gastric evacuation, are available.

Radiological methods do not determine the pattern and their accuracy in measuring the end point has been questioned (Hunt and Spurrell, 1951; Horton, Ross, and Darling, 1965). The method using radioactive chromium and surface scanning described by Griffith, Owen, Kirkman, and Shields (1966) excludes premenopausal women and, therefore, some patients with gastric ulceration. The serial test meal (Hunt and Spurrell, 1951) maintains a high degree of accuracy in determining both rate and pattern and can simultaneously measure gastric secretion. This test has the further advantage of measuring certain 'characteristics' of emptying which are more informative than emptying time alone. Modified Hunt techniques, such as that used by Aylett (1965), assume constant emptying pattern and characteristics in all stomachs.

As the serial test meal takes several days to complete, with daily nasogastric intubation, a new test has been designed to obtain the emptying pattern for an individual stomach in a single test. This gives the test a more clinical application. A dye dilution and double-sampling technique is used. Double sampling is introduced to overcome the accumulation of error in dye dilution methods which was shown by Hollander and Glickstein (1940) to exist. It also obviates the necessity of enıtying the stomach to determine the volume of its contents; a series of measurements can be made as the stomach empties and a complete pattern of emptying obtained in a single test lasting a few hours. The volume of gastric secretion can be determined at

${ }^{1}$ This work was undertaken during the tenure of a Royal Victoria Hospital research fellowship. the same time and consequently a precise rate of gastric evacuation obtained.

\section{PRINCIPLE}

The volume of fluid in a container can be ascertained by determining the increase in concentration of a dye produced by the addition of a small concentrated measure of the same dye.

In Fig. $1 \quad V_{1}=$ Volume to be determined $C_{1}=$ Initial concentration of dye in $V_{1}$

$V_{2}=$ Volume of the measure of dye to be added to $\mathrm{V}_{1}$

$\mathrm{C}_{2}=$ Concentration of the added dye

$\mathrm{C}_{3}=$ Final concentration of the mixture

The mass of dye in $V_{1}$ is given by $m_{1}=V_{1} C_{1}$

The mass of dye in $V_{2}$ is given by $m_{2}=V_{2} C_{2}$

The mass of dye in $V_{1}+V_{2}$ is given by $m_{3}=$

$\left(\mathrm{V}_{1}+\mathrm{V}_{2}\right) \mathrm{C}_{3}$

$\mathrm{m}_{1}+\mathrm{m}_{2}=\mathrm{m}_{3}$

$\therefore \mathrm{V}_{1} \mathrm{C}_{1}+\mathrm{V}_{2} \mathrm{C}_{2}=\left(\mathrm{V}_{1}+\mathrm{V}_{2}\right) \mathrm{C}_{3}$

$\therefore \mathrm{V}_{1}=\mathrm{V}_{2}\left(\mathrm{C}_{2}-\mathrm{C}_{3}\right)$

$$
\mathrm{C}_{3}-\mathrm{C}_{1}
$$

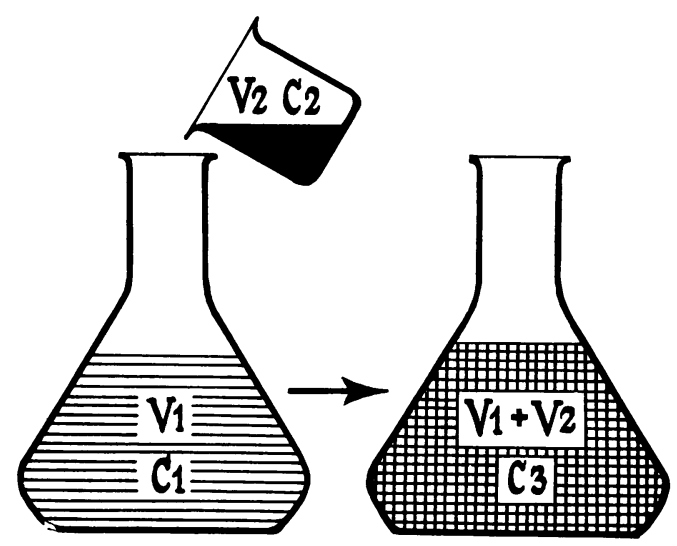

FIG. 1. Principle of double sampling technique. 
If the concentration of a solution before and after the addition of a measure of known volume and concentration can be determined, the original volume can be calculated from this equation.

\section{ANALYTICAL TECHNIQUES}

The dye used in the test is phenol red. To make up the test meal and to determine the concentration of phenol red, Hunt's procedure (Hunt, 1954) has been used with minor modifications. A spectrophotometer has been employed rather than a colorimeter to improve the precision and smaller sample volumes of gastric contents are used.

A stock solution of approximately $500 \mathrm{ppm}$ is made up and this constitutes the concentrated measure used in the test. The test meal, $750 \mathrm{ml}$ of approximately $30 \mathrm{ppm}$, is made up from the stock solution by diluting with distilled water. The $\mathrm{pH}$ of the meal and of the concentrated measure is adjusted to 7.0 with sulphuric acid. The buffer solution is made by dissolving $27.5 \mathrm{~g}$ of trisodium orthophosphate, $\mathrm{Na}_{3} \mathrm{PO}_{4} 12 \mathrm{H}_{2} \mathrm{O}$ in 1 litre of water.

DETERMINATION OF PHENOL RED CONCENTRATION Gastric contents, $4 \mathrm{ml}$, centrifuged to remove mucus and gastric debris if present, plus $20 \mathrm{ml}$ buffer solution, are made up to $100 \mathrm{ml}$ in a volumetric flask and filtered. The purple colour developed is measured on an Optica CF4 spectrophotometer at $560 \mathrm{~m} \mu$ using a $1 \mathrm{~cm}$ cell. A linear relationship exists between concentration and optical density up to at least $200 \mathrm{ppm}$ which is well above the maximum concentration encountered in this test. The concentration of the samples can either be read from a calibration chart or calculated from the equation of its curve.

Before the concentrated stock solution and test meal are used, their exact concentration is determined on the day of the test, since a very slight daily change in concentration has been noted.

\section{TECHNIQUE OF TEST}

1 A nasogastric tube is passed into the stomach of a fasting patient, the resting juice removed, and the stomach washed out with $200 \mathrm{ml}$ distilled water. The patient rests for a minimum of 20 minutes until he feels comfortable with the gastric tube in situ.

2 The patient drinks $750 \mathrm{ml}$ of the test meal, the drinking time being between one and four minutes, and the time is noted at the beginning of the meal. The patient remains in a standard position, sitting upright on a chair throughout the test. $\mathrm{He}$ is also asked to refrain from swallowing saliva and to use a sputum jar.

3 At exactly 10 minutes $7-8 \mathrm{ml}$ of gastric contents is withdrawn. The plunger of the syringe is then removed and $20 \mathrm{ml}$ of the concentrated stock solution is added by pipette. Mixing in the stomach is achieved by withdrawing and re-inserting syringefuls of gastric contents for about 45 seconds, and following this a second sample of gastric contents is removed (Fig. 2). From these two samples concentrations $C_{1}$ and $C_{3}$ are determined and the unknown volume calculated from equation $(v)$.

4 The above procedure is repeated at required intervals until the stomach is almost empty.

5 Some difficulty in withdrawing contents may now be encountered and it may be necessary to move the gastric tube to find the remaining fluid. When this point is reached, as much as possible of the remaining contents is withdrawn and measured. The stomach is then washed out with $200 \mathrm{ml}$ of water and the true residual volume calculated from the concentrations of dye in the residual contents and washout (Hunt and Spurrell, 1951). This final procedure has been included as a check on the double sampling technique.

Certain points in this method require further discussion. The tip of the tube should lie in the body of the stomach and there should be no slack in the tube; the tip should not reach the pyloric antrum. This position is checked by $x$-ray screening and the tube is then secured firmly to the upper lip with adhesive tape. A pipette is used to add the concentrated solution, since it is important that this volume should be accurate as any error would be magnified when applied to the mathematical equation. The denominator in this equation is the difference between two relatively large values and it is therefore advantageous

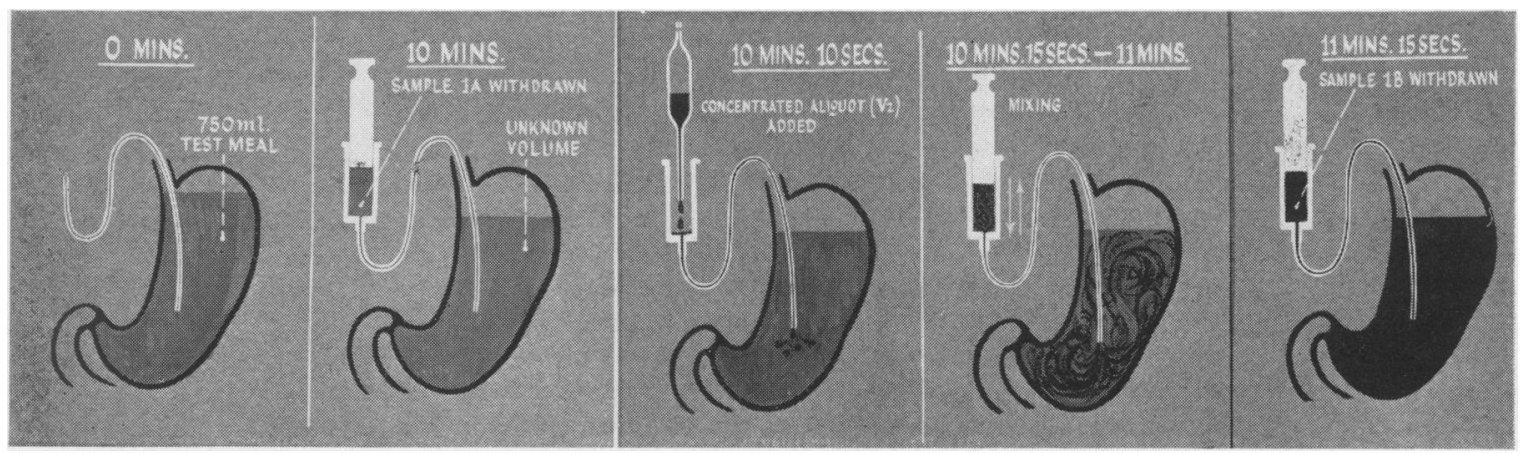

FIG. 2. Double sampling test meal. At $0 \mathrm{~min}, 750 \mathrm{ml}$ test meal ingested; at $10 \mathrm{~min}$, sample withdrawn from stomach; at $10 \mathrm{~min} 10 \mathrm{sec}$ (approx.), concentrated measure of dye added; at $10 \mathrm{~min} 15 \mathrm{sec}$ to $11 \mathrm{~min}$ (approx.), mixing of dye in stomach; at 11 min $15 \mathrm{sec}$ (approx.), second sample withdrawn jrom stomach. 
to maintain it as large as possible. This is achieved by making the volume of the added solution large at the beginning of the test, when the volume in the stomach is large, and decreasing it as the test proceeds. Experience has shown that the added volumes can be standardized as indicated in Table $I$.

TABLE I

STANDARDIZATION OF ADDED VOLUMES

\begin{tabular}{llllll} 
Intervals of Test & Time (min) \\
\hline 10 & 20 & 30 & 40 & 50 & $\begin{array}{l}60 \text { to } \\
\text { End of Test }\end{array}$
\end{tabular}

Volume of

$\begin{array}{lllllll}\text { added solution }(\mathrm{ml}) & 20 & 15 & 10 & 10 & 10 & 5\end{array}$

Additional information can be gained from this test. If the concentrations of $\mathrm{H}^{+}$and $\mathrm{Cl}^{-}$are measured in each sample the gastric juice secreted can be assessed. As a further step, where information about intraluminar pressure is required, a side arm can be attached to the gastric tube and pressure recordings made as the stomach empties.

\section{VALIDITY OF TEST}

The validity of this test has been assessed in a glass model and also in human stomachs.

CALCULATION OF VOLUME IN VITRO Forty known volumes in a static glass model were calculated by this technique. Then, using a siphon, an emptying model was constructed and 20 estimations were made, limiting the sampling time to two minutes. The percentage error in measuring volumes between 100 and $750 \mathrm{ml}$ ranged from 0.3 to 9 . For volumes below $100 \mathrm{ml}$ the error was never greater than $8 \mathrm{ml}$.

HOMOGENEOUS MIXING Mixing by the method described above was applied to a glass stomach and it was found that mixing for 30 seconds was adequate. Samples taken after longer periods of mixing and after thorough shaking of the glass model showed no change in concentration.

CALCULATION OF VOLUME IN HUMAN STOMACH To validate the test in human stomachs unknown volumes of fluids in a volunteer's stomach were determined by the double sampling technique and immediately afterwards as much as possible of the fluid was removed and measured. After washing out the stomach with $200 \mathrm{ml}$ of water the volume of any remaining fluid was calculated from the concentrations of dye in the removed fluid and in the washed out fluid. This volume was added to the volume of removed fluid to find the true volume (Hunt and Spurrell, 1951). Forty comparisons were made and the percentage difference in the calculations ranged from 2 to 10 for volumes above $100 \mathrm{ml}$; for volumes below $100 \mathrm{ml}$ the difference was never greater than $7 \mathrm{ml}$.

COMPLETE TEST IN HUMANS The complete test was compared with the serial test meal (Hunt and Spurrell, 1951) in several subjects. The excellent correlation between the two tests is shown in Figure 3.

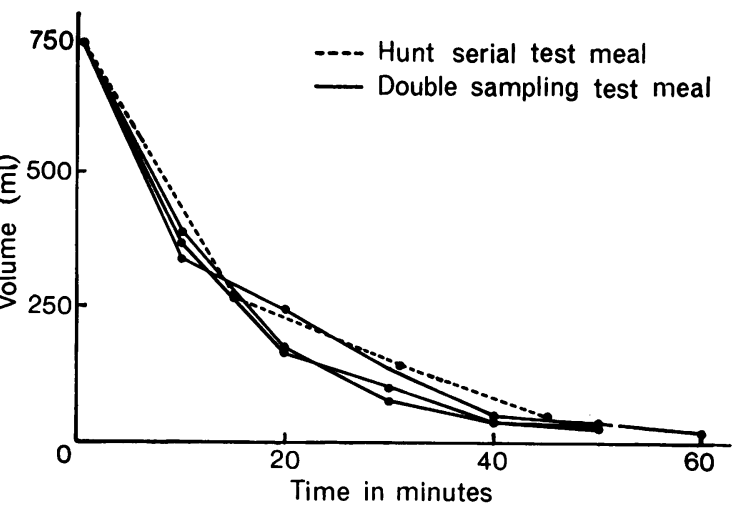

FIG. 3. Three double sampling test meals and one serial test meal carried out on the same subject to show the close correlation between the two tests.

REPRODUCIBILITY OF TEST Hunt and Spurrell (1951) have shown that there is very little daily variation in the emptying pattern of an individual stomach. The present test has been repeated on several volunteers and the reproducibility of results found to be very satisfactory (Fig. 4).

ABNORMAL STOMACHS A normal stomach was compared with a stomach with obvious clinical and radiological evidence of pyloric stenosis. The test demonstrated the expected gross delay in emptying in the abnormal stomach.

\section{INTERPRETATION OF RESULTS}

Hunt and Spurrell (1951) found that a linear relationship existed when the logarithm of the volume remaining in the stomach was plotted against time. However, Hopkins (1966), who reviewed Hunt's work, stated that the regression line was closer to a linear relationship when the square root of the remaining volume was plotted against time.

The regression equations for both the logarithm and the square root of the volumes estimated in each of 79 tests have been calculated, with the aid of a computer, using the method of least squares 


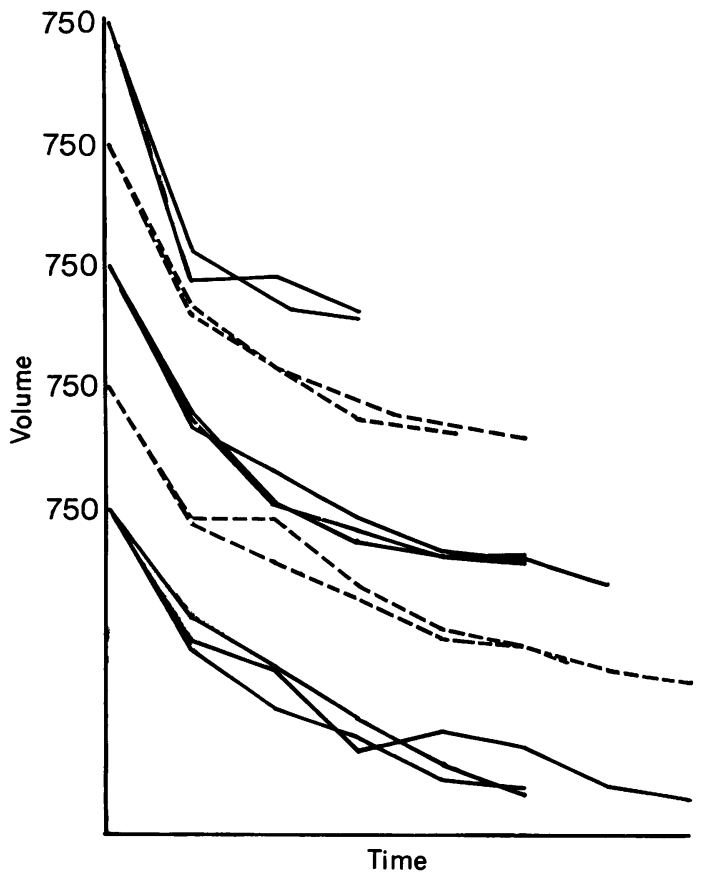

FIG. 4. Double sampling test meal performed two or three times on each of five different subjects to show the reproducibility of the test.

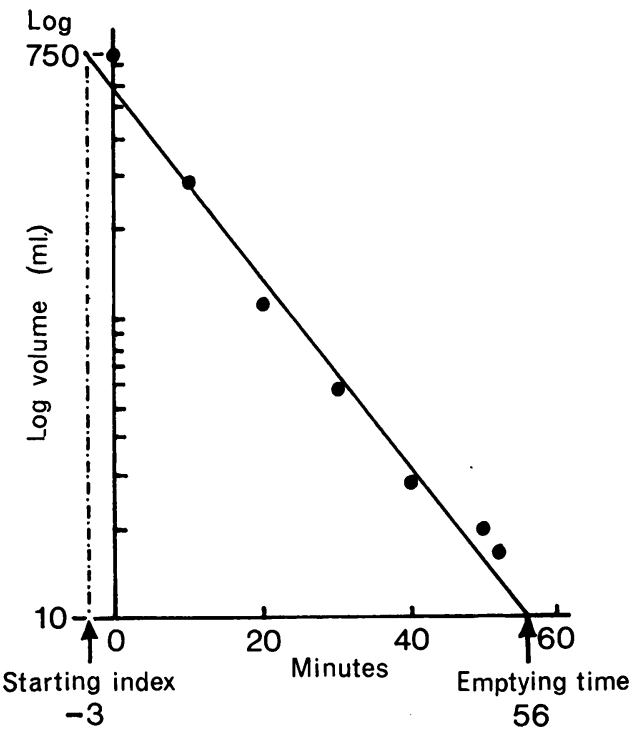

FIG. 5. Negative starting index indicated by the regression line reaching Log. 750 at time -3 min. and the coefficient of variation for each equation obtained. In five cases the coefficient of variation indicated a square root relationship; for the remaining 74 the coefficient of variation indicated an exponential relationship. It was therefore decided that the defining parameters should be calculated from the exponential relationship.

The three 'characteristics' of emptying as originally described by Hunt and Spurrell (1951) have been calculated from the exponential regression equation of each case. 1 'Emptying time' is defined as the time taken for the volume of gastric contents to become reduced to $10 \mathrm{ml}$. 2 'Half-life' is defined as the time required for the volume in the stomach to fall by half. 3 'Starting index' is defined as the number of minutes before or after zero time at which the extrapolated regression line reached log. 750 (Figs. 5 and 6). A negative starting index indicates that the initial phase of emptying is rapid and a positive index occurs when initial emptying is slow.

In three cases of gastric ulceration neither an exponential nor a square root relationship existed. In these cases there was obvious delay in emptying; the stomach started to empty in a normal fashion but there appeared to be difficulty in expressing the final $100-200 \mathrm{ml}$ of contents (Fig. 7).

\section{RESULTS}

This test has been carried out on three groups of subjects. Twenty normal controls have been com-

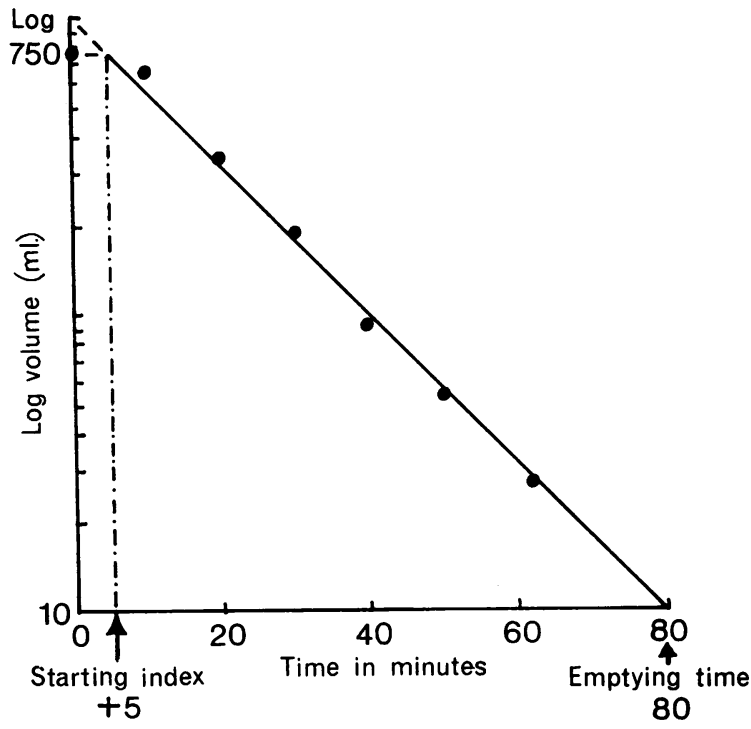

FIG. 6. Positive starting index indicated by the regression line reaching Log. 750 at time +5 min. 


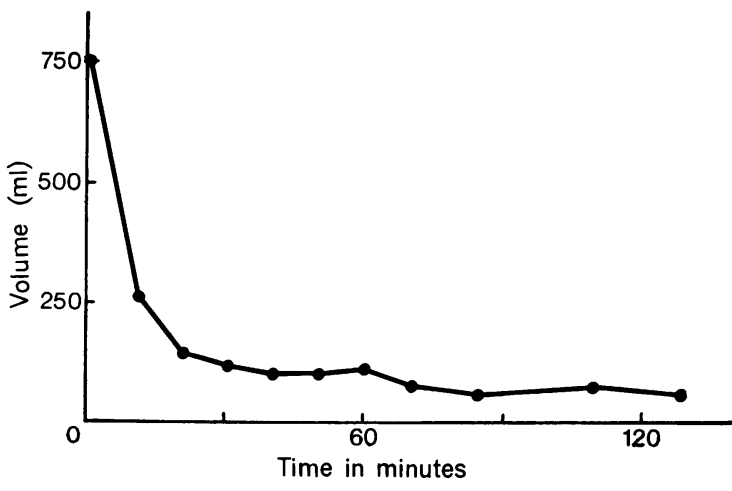

FIG. 7. 'Abnormal' pattern of gastric emptying; initial pattern of emptying is normal but there is difficulty in expressing the final 100-200 $\mathrm{ml}$ of test meal.

pared with 20 unselected cases of duodenal ulceration and 20 cases of gastric ulceration. Three gastric ulcer patients who showed an abnormal emptying pattern have not been included. Several subjects had more than one test performed and in these cases the mean result was taken.

Tables II, III, and IV indicate the 'starting index', 'half-life', and 'emptying time' in the three groups of subjects. There is a highly significant increase in both the emptying time and half-life in patients with gastric ulceration when compared with normal subjects $(\mathrm{P}<0.001)$ and also with duodenal ulcer patients $(0.05>P>0.02)$. There is no significant

TABLE II

RESULTS OF DOUBLE-SAMPLING TEST MEAL IN NORMAL SUBJECTS

\begin{tabular}{lllllll} 
Subject & Age & Sex & $\begin{array}{l}\text { No. of } \\
\text { Tests }\end{array}$ & $\begin{array}{l}\text { Starting } \\
\text { Index } \\
\text { (Minutes) }\end{array}$ & $\begin{array}{l}\text { Half- } \\
\text { life } \\
\text { (Minutes) }\end{array}$ & $\begin{array}{l}\text { Emptying } \\
\text { Time } \\
\text { (Minutes) }\end{array}$ \\
\hline 1 & 19 & M & 1 & +1 & 8 & 50 \\
2 & 24 & M & 1 & +7 & 7 & 51 \\
3 & 35 & M & 1 & +4 & 8 & 55 \\
4 & 22 & M & 8 & +1 & 10 & 61 \\
5 & 71 & M & 1 & +8 & 9 & 62 \\
6 & 31 & M & 4 & 0 & 10 & 62 \\
7 & 28 & M & 1 & 8 & 9 & 66 \\
8 & 25 & M & 1 & 6 & 10 & 69 \\
9 & 24 & M & 1 & 0 & 11 & 69 \\
10 & 26 & F & 1 & -2 & 12 & 70 \\
11 & 26 & F & 1 & 0 & 12 & 73 \\
12 & 23 & F & 1 & -3 & 12 & 73 \\
13 & 27 & M & 1 & 0 & 12 & 75 \\
14 & 30 & M & 1 & 9 & 11 & 78 \\
15 & 31 & M & 1 & 0 & 13 & 78 \\
16 & 20 & M & 1 & 16 & 11 & 85 \\
17 & 23 & F & 1 & 0 & 14 & 86 \\
18 & 21 & F & 1 & -1 & 14 & 88 \\
19 & 22 & F & 4 & 2 & 14 & 89 \\
20 & 24 & M & 2 & 2 & 15 & 98 \\
& & & & & & \\
& Mean & & & +3 & 11 & 72 \\
& Standard deviation & $4 \cdot 7$ & $2 \cdot 2$ & $13 \cdot 1$ \\
& & & & & &
\end{tabular}

TABLE III

RESULTS OF DOUBLE-SAMPLING TEST MEAL IN DUODENAL ULCER PATIENTS

\begin{tabular}{llllcll} 
Subject & Age & Sex & $\begin{array}{l}\text { No. of } \\
\text { Tests }\end{array}$ & $\begin{array}{l}\text { Starting } \\
\text { Index } \\
\text { (Minutes) }\end{array}$ & $\begin{array}{l}\text { Half- } \\
\text { life } \\
\text { (Minutes) }\end{array}$ & $\begin{array}{l}\text { Emptying } \\
\text { Time } \\
\text { (Minutes) }\end{array}$ \\
\hline 1 & 36 & M & 1 & 0 & 6 & 39 \\
2 & 60 & M & 1 & -3 & 9 & 56 \\
3 & 36 & M & 2 & -2 & 10 & 56 \\
4 & 56 & M & 1 & 4 & 9 & 59 \\
5 & 34 & M & 1 & 0 & 10 & 61 \\
6 & 36 & M & 1 & 5 & 10 & 69 \\
7 & 47 & F & 1 & 1 & 11 & 69 \\
8 & 60 & M & 2 & -1 & 11 & 70 \\
9 & 37 & M & 1 & -3 & 12 & 70 \\
10 & 47 & M & 1 & 7 & 12 & 80 \\
11 & 59 & F & 1 & 7 & 12 & 83 \\
12 & 62 & M & 1 & 5 & 13 & 83 \\
13 & 68 & M & 1 & 0 & 13 & 83 \\
14 & 39 & F & 1 & 4 & 14 & 93 \\
15 & 40 & M & 1 & 3 & 14 & 93 \\
16 & 43 & M & 1 & 1 & 15 & 96 \\
17 & 36 & M & 1 & 5 & 16 & 106 \\
18 & 20 & M & 1 & 2 & 18 & 113 \\
19 & 41 & F & 1 & 7 & 18 & 118 \\
20 & 53 & M & 1 & 12 & 19 & 128 \\
& Mean & & $2 \cdot 7$ & 13 & 81 \\
& Standard deviation & $3 \cdot 9$ & $3 \cdot 4$ & $23 \cdot 1$ \\
& & & & & &
\end{tabular}

TABLE IV

RESULTS OF DOUBLE SAMPLING TEST MEAL IN GASTRIC ULCER PATIENTS

\begin{tabular}{rlllcll} 
Subject & Age & Sex & $\begin{array}{l}\text { No. of } \\
\text { Tests }\end{array}$ & $\begin{array}{l}\text { Starting } \\
\text { Index } \\
\text { (Minutes) }\end{array}$ & $\begin{array}{l}\text { Half- } \\
\text { life } \\
\text { (Minutes) }\end{array}$ & $\begin{array}{l}\text { Emptying } \\
\text { Time } \\
\text { (Minutes) }\end{array}$ \\
\hline 1 & 44 & M & 1 & 11 & 8 & 60 \\
2 & 39 & F & 1 & -2 & 10 & 62 \\
3 & 56 & M & 1 & 0 & 12 & 71 \\
4 & 70 & F & 2 & -2 & 13 & 73 \\
5 & 46 & F & 1 & -1 & 12 & 77 \\
6 & 52 & M & 1 & 5 & 12 & 79 \\
7 & 41 & F & 2 & 2 & 13 & 83 \\
8 & 51 & F & 1 & 8 & 13 & 86 \\
9 & 72 & F & 1 & 0 & 14 & 87 \\
10 & 52 & M & 1 & 4 & 14 & 92 \\
11 & 43 & F & 1 & 0 & 15 & 93 \\
12 & 55 & M & 1 & 1 & 15 & 95 \\
13 & 41 & M & 1 & 2 & 16 & 103 \\
14 & 47 & F & 1 & 12 & 16 & 109 \\
15 & 32 & F & 2 & 9 & 16 & 112 \\
16 & 35 & F & 1 & 3 & 18 & 117 \\
17 & 49 & F & 1 & 0 & 25 & 154 \\
18 & 55 & F & 1 & 12 & 24 & 160 \\
19 & 40 & M & 1 & 2 & 18 & 174 \\
20 & 32 & M & 1 & 7 & 31 & 201 \\
& & & & & & \\
& Mean & & $3 \cdot 7$ & 16 & 104 \\
& Standard deviation & $4 \cdot 6$ & $6 \cdot 1$ & 38.9 \\
& & & & & &
\end{tabular}

difference in the rate of emptying of normal subjects and patients with duodenal ulceration. Comparisons of the 'starting index' in the three groups of subjects show no significant difference.

\section{DISCUSSION}

This test, which has been entitled the double samp- 
ling test meal, has been described and certain advantages over other methods are claimed. The test is easy to perform and is completed in one to two hours with little discomfort to the patient. It is accurate if a strict practical and laboratory discipline is maintained. Double sampling avoids any cumulative error since each sample is determined independently of any previous calculation and it also allows a series of measurements to be made as the stomach empties. Bloom, Jacobson, and Grossman (1967) have indicated that there may be some loss of phenol red from the canine stomach. An advantage of double sampling is that the volume calculation is independent of any action of dye in the stomach. The only assumption made is that the amount of dye absorbed or secreted by the stomach during the sampling period (about one minute) is negligible.

A fluid meal has been used and it could be argued that this gives no indication of the emptying pattern of a normal mixed meal. Similar patterns of emptying have, however, been demonstrated by Griffith et al. (1966) for a mixed meal. The advantages of a fluid meal are that it is easily standardized for comparisons and it provides a useful vehicle for accurate concomitant studies, such as acid secretion.

The results of this test confirm previous work (Oberhelman, 1959; Burge, 1964) that the rate of emptying is slower in patients with gastric ulceration than in both normal controls and patients with duodenal ulceration.

Both the emptying time and half life are increased in gastric ulcer patients but there is no difference in the starting index. This would indicate that the delayed rate of emptying is due to a decreased propulsive power of the stomach or to an increased resistance to emptying which is maintained throughout the emptying process rather than an initial delay in starting emptying. A small group of gastric ulcer patients show an abnormal pattern of emptying with delay in expressing the final part of the meal.

\section{SUMMARY}

A new test has been described to measure the rate of gastric emptying. It utilizes a dye dilution and double sampling technique to calculate the volume of gastric contents.

The test is simple to perform and can be used clinically. It can also be used to give information about acid secretion.

The results of this test indicate that the rate of gastric emptying is slower in patients with gastric ulceration than in both normal subjects and patients with duodenal ulceration.

1 am indebted to the surgeons of the Royal Victoria Hospital and the Belfast City Hospital for permission to study patients under their care, and to Mr. T. L. Kennedy and Dr. A. M. Connell for advice and help throughout the course of this study. I thank Miss M. Simpson for secretarial help and Staff Nurse E. Whieldon for help with patients. My thanks also go to Messrs. R. Wood and $\mathbf{G}$. Smith for the diagrams.

\section{REFERENCES}

Aylett, P. (1965). Gastric emptying and secretion in patients with diabetes mellitus. Gut, 6, 262-265.

Bloom, D. S., Jacobson, E. D., and Grossman, M. I. (1967). Validation of dilution indicators in the stomach. Gastroenterology, 52, 205-210.

Burge, H. (1964). Vagotomy. Arnold, London.

Griffith, G. H., Owen, G. M., Kirkman, S., and Shields, R. (1966). Measurement of rate of gastric emptying using chromium-51. Lancet, 1, 1244-1245.

Hollander, F., and Glickstein, J. (1940). Secretory studies in whole stomachs: the dilution indicator technique and its precision measures. Amer. J. dig. Dis., 7, 386-391.

Hopkins, A. (1966). The pattern of gastric emptying: a new view of old results. J. Physiol. (Lond.), 182, 144-149.

Horton, R. E., Ross, F. G. M., and Darling, G. H. (1965). Determination of the emptying time of the stomach by use of enteric-coated barium granules. Brit. med. J., 1, 1537-1539.

Hunt, J. N. (1954). The inhibitory action of sucrose on gastric digestive activity in patients with peptic ulcer. Guy's Hosp. Rep., 103, 161-173.

- and Spurrell, W. R. (1951). The pattern of emptying of the human stomach. J. Physiol. (Lond.), 113, 157-168.

Oberhelman, H. A. (1959). In The Physiology and Treatment of Peptic Ulcer, edited by J. G. Allen. University of Chicago Press, Chicago. 